\title{
KRUMEICH, Gerd, LEHMANN, Hartmut, « Gott mit uns ». Nation, Religion und Gewalt im 19. und frühen 20. Jahrhundert
}

Anne Duménil

\section{(2) OpenEdition}

Édition électronique

URL : http://journals.openedition.org/ifha/1220

DOI : $10.4000 /$ ifha. 1220

ISSN : 2198-8943

Éditeur

IFRA - Institut franco-allemand (sciences historiques et sociales)

Référence électronique

Anne Duménil, « KRUMEICH, Gerd, LEHMANN, Hartmut, "Gott mit uns ». Nation, Religion und Gewalt im 19. und frühen 20. Jahrhundert », Revue de l'IFHA [En ligne], Date de recension, mis en ligne le 01 janvier 2002, consulté le 22 septembre 2020. URL : http://journals.openedition.org/ifha/1220 ; DOI : https:// doi.org/10.4000/ifha. 1220

Ce document a été généré automatiquement le 22 septembre 2020.

(CIFHA 


\title{
KRUMEICH, Gerd, LEHMANN, Hartmut, " Gott mit uns ». Nation, Religion und Gewalt im 19. und frühen 20. Jahrhundert
}

\author{
Anne Duménil
}

1 Issues d'un colloque organisé au printemps 1998 par le Max-Planck-Institut für Geschichte, les quinze contributions de ce dense volume explorent les liens complexes qui, dans un long XIXe s. (de 1789 à 1914), unissent religion, nation et violence.

2 L'affirmation nationale a largement emprunté la voie de la stigmatisation de l'ennemi ennemi de l'intérieur, ennemi de l'extérieur - qui mobilise de puissantes antinomies, génératrices d'identité, opposant soi et l'autre, l'étranger et le national et, finalement, le bien et le mal. Quatre figures de cet autre antagonique sont ici privilégiées : P. BECKER examine la construction de l'image du criminel, B. PLEITNER tente de décrire la figure du Polonais dans le discours national allemand à travers une trop succincte étude de presse et P. SCHUMANN explore comment est élaborée la dichotomie entre " le mauvais Juif » et le « bon allemand » dans deux succès de librairie, Soll und haben de Gustav Freytag et Der Hungerpastor de Wilhelm Raab. Fort stimulante est la réflexion de U. SCHNEIDER sur le terme "welsch», courant dans la littérature du XIXe s. Le mot qui ne cesse d'évoluer depuis le Moyen Âge acquiert dans le contexte des guerres napoléoniennes une forte charge idéologique sans cependant parvenir à s'imposer dans le lexique courant : il laisse place, dans la deuxième moitié du siècle, à l'expression d'« ennemi héréditaire ».

3 La sacralisation de la nation et la nationalisation des religions forment ici le centre de la réflexion. Riche d'une belle iconographie, l'article d'E. PELZER montre comment la poésie patriotique des guerres de libération assume une fonction d'anticipation imaginaire de la nation, entité collective et valeur spirituelle, et fait de la diabolisation de Napoléon un ressort de la construction de la conscience nationale. Les écrits sur la religiosité de Bismarck étudiés par L. HÖLSCHER révèlent également 
l'instrumentalisation dont les arguments religieux font l'objet dans le discours politique. H. LEHMANN examine comment s'impose durablement la figure, établie par Treitschke dans son discours de novembre 1883, d'un Luther contribuant, par ses qualités germaniques, à l'accomplissement de la destinée manifeste de la nation. Dans le seul article qui ne soit pas consacré au cas allemand, D. MOLLENHAUER montre que, sans partager la même interprétation des causes de la défaite de 1870, les différents courants du catholicisme français ont en commun une lecture providentialiste de la guerre : son issue, signe de Dieu, est aussi un appel à la rechristianisation de la nation et la guerre revitalise la question religieuse. J. VOGEL établit que la politique impériale de la mémoire élaborée par Guillaume II autour de la figure de son grand-père comporte systématiquement une double dimension, guerrière et religieuse : la statue équestre de Berlin souligne le caractère militaro-dynastique du culte rendu à Guillaume Ier, l'église du souvenir met en valeur sa religiosité personnelle, érigée en fondement de l'unité de la nation, et le monument du Kyffhäuser - le seul à enraciner durablement le mythe dynastique - mobilise la référence légendaire au service d'un imaginaire national contemporain. Retenant trois niveaux d'analyse - le protestantisme comme instance de légitimation du principe monarchique autoritaire, les nouvelles classes moyennes comme acteurs d'une radicalisation du nationalisme, l'influence des courants ultranationalistes émanant de groupes religieux extérieurs aux églises établies -, G. HÜBINGER incite à se méfier des simplifications abusives et explore les formes de nationalisme propres aux différents groupements associatifs d'influence protestante. Dans un bel article consacré au "Choral de Leuthen », B.R. KROENER déconstruit ce lieu de mémoire prussien et allemand où se mêlent étroitement foi et violence. À partir d'un rite de bataille banal - le service religieux qui suit le combat - s'est élaborée une construction symbolique complexe, alliant les composantes religieuse et nationale. Dans les années de fondation de l'Empire allemand, militaires, artistes et historiens multiplient les références à Frédéric II, qui incarne les valeurs prussiennes dont le protestantisme serait le ferment. Le mythe frédéricien, qui tient dès lors une place centrale dans l'imaginaire national, s'affirme plus fortement encore après 1918. Instrumentalisé par la propagande hitlérienne, qui entend récupérer à son profit le capital mémoriel de la Prusse, le choral devient le symbole d'une communauté nationale prête à l'ultime sacrifice. Dans une tonalité discordante, S. FÖRSTER pense pouvoir dépeindre les officiers supérieurs de l'époque wilhelminienne comme étrangers aux préoccupations religieuses, le processus de sécularisation ayant substitué à l'eschatologie religieuse la croyance en un social-darwinisme à prétention scientifique : pour eux, la Grande Guerre n'aurait pas été une croisade, mais simplement une guerre idéologique.

4 Trois articles explorent plus spécifiquement ce thème. G. KRUMEICH interroge la pertinence de la notion de guerre sainte appliquée au premier conflit mondial et relève un paradoxe : la dimension eschatologique du conflit aurait été beaucoup plus présente dans la France républicaine, où la guerre est effectivement conçue comme une croisade. En Allemagne, comme le montre W. MOMMSEN, le conflit a certes été accompagné d'une puissante mobilisation spirituelle : prêtres, pasteurs et théologiens interprètent le conflit comme œuvre de Dieu et la victoire future comme signe du salut accordé au peuple allemand. Mais la guerre se prolongeant, cette lecture rencontre de moins en moins l'assentiment des fidèles alors que des voix, certes minoritaires, contestent la possibilité de connaître les desseins divins et appellent à une paix négociée. Ce contexte de réveil religieux, également marqué par une puissante concurrence entre 
confessions, a permis aux prêtres et à la hiérarchie catholiques d'affirmer leur identité et leur rôle. R. HAIDL étudie spécifiquement leur intervention dans la question des foyers de soldats : ces structures, développées afin de soustraire les combattants aux périls supposés de l'arrière, constituaient des " lieux de mission " privilégiés où les aumôniers catholiques entendaient défendre leur influence face aux protestants.

5 Enfin, dans un article qui revendique sa posture critique, F.W. Graf analyse la place du religieux dans l'historiographie allemande : après avoir dénoncé le simplisme d'analyses longtemps dominées par le concept de sécularisation, il identifie le renouveau permis par les approches de la nouvelle histoire culturelle, mais déplore que l'isolement disciplinaire de la théologie prive les autres disciplines d'instruments analytiques indispensables permettant, par exemple, d'étudier la sémantique religieuse et les théologies implicites qui sous-tendent les conceptions de la nation.

6 Ces études, dans leur diversité, manifestent combien la prise en compte du paradigme religieux renouvelle les études sur le nationalisme, en particulier dans ses formes les plus radicalisées.

7 Anne DUMÉNIL 